\title{
Odin-OSIRIS detection of the Chelyabinsk meteor
}

\author{
L. A. Rieger, A. E. Bourassa, and D. A. Degenstein \\ Institute of Space and Atmospheric Studies, University of Saskatchewan, Saskatchewan, Canada \\ Correspondence to: L. A. Rieger (landon.rieger@usask.ca)
}

Received: 26 August 2013 - Published in Atmos. Meas. Tech. Discuss.: 23 September 2013

Revised: 12 February 2014 - Accepted: 13 February 2014 - Published: 24 March 2014

\begin{abstract}
On 15 February 2013 an 11000 ton meteor entered Earth's atmosphere southeast of Chelyabinsk, creating a large fireball at $23 \mathrm{~km}$ altitude. The resulting stratospheric aerosol loading was detected by the Ozone Mapping and Profiler Suite (OMPS) in a high-altitude polar belt. This work confirms the presence and lifetime of the stratospheric debris using the Optical Spectrograph and InfraRed Imaging System (OSIRIS) onboard the Odin satellite. Although OSIRIS coverage begins in mid-March, the measurements show a belt of enhanced scattering near $35 \mathrm{~km}$ altitude between $50^{\circ} \mathrm{N}$ and $70^{\circ} \mathrm{N}$. Initially, enhancements show increased scattering of up to $15 \%$ over the background conditions, decaying in intensity and dropping in altitude until they are indistinguishable from background conditions by mid-May. An inversion is also attempted using the standard OSIRIS processing algorithm to determine the extinction in the meteoric debris.
\end{abstract}

\section{Introduction}

The Optical Spectrograph and InfraRed Imaging System (OSIRIS) is a limb scatter instrument launched in 2001 on the Odin satellite (Llewellyn et al., 2004). Odin was placed in a polar, sun-synchronous orbit at $600 \mathrm{~km}$ altitude with an inclination of $98^{\circ}$. OSIRIS views in the orbital plane provide measurements from $82^{\circ} \mathrm{S}$ to $82^{\circ} \mathrm{N}$, provided the tangent point is sunlit. As Odin orbits the satellite nods to scan the instrument line of sight vertically through tangent heights ranging from 7 to $65 \mathrm{~km}$ during typical operation. The optical spectrograph measures wavelengths from 275 to $810 \mathrm{~nm}$ with approximately $1 \mathrm{~nm}$ resolution. Wavelengths in Hartley-Huggins and Chappius bands are used to retrieve ozone profiles, while the longer wavelengths are useful in the retrieval of stratospheric aerosols. Although not typically used to measure meteoric deposition in the stratosphere, the Chelyabinsk meteor allows for a unique opportunity due to its size and high-altitude explosion.

On 15 February 2013 the meteor entered the atmosphere at a shallow angle southeast of Chelyabinsk. Traveling at $18 \mathrm{~km} \mathrm{~s}^{-1}$ the meteor exploded at an altitude of $23.3 \mathrm{~km}$. With an approximate mass of 11000 tons this was the most energetic impact event since the 1908 Tunguska event, also in Russia (Yeomans and Chodas, 2013). Due to solar illumination conditions OSIRIS begins measuring mid-to-high northern latitudes near the end of February; however, in 2013 engineering diagnostic modes on the instrument power supply prevented sustained measurements of higher latitudes until mid-March. While this precluded measurements of the initial impact, subsequent measurements show the remnants of the explosion still present in the stratosphere for the months following the impact.

This paper investigates the OSIRIS measurements of the meteoric debris and its subsequent removal from the stratosphere. In Sect. 2 the OSIRIS measurements are outlined and scans showing high-altitude enhancements are examined. Section 3 explores the spacial distribution of the enhancements and their lifetime. While this is the main goal of the paper, an attempt is made in Sect. 4 to retrieve the extinction of the meteoric debris using the standard OSIRIS processing techniques. Results of this study are briefly compared to the results of Gorkavyi et al. (2013).

\section{OSIRIS measurements}

The long path lengths of OSIRIS limb measurements provide excellent sensitivity to extinction as low as $10^{-5} \mathrm{~km}^{-1}$ under typical conditions in the stratosphere. This is particularly true at the longer optical spectrograph wavelengths where the relative contribution of aerosol scattering to Rayleigh scattering 


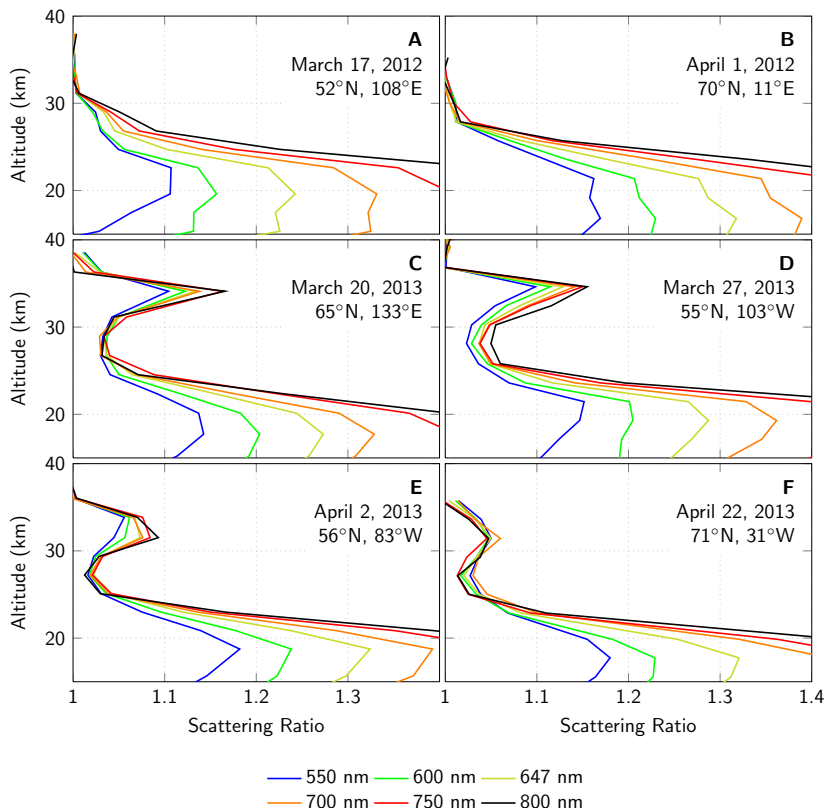

Fig. 1. Scattering ratios from six OSIRIS scans. Panels (A) and (B) are scans from 2012 and show typical background conditions. Panels (C) through (F) show scans with enhanced scattering at high altitudes. The enhancements near 30 to $35 \mathrm{~km}$ are attributed to the meteor, while the lower peak near $20 \mathrm{~km}$ is the Junge layer. Scattering ratios are shown at 6 wavelengths in approximately $50 \mathrm{~nm}$ intervals from 550 to $800 \mathrm{~nm}$.

is higher. The ratio of total radiance to that expected from an aerosol-free atmosphere provides a good qualitative measure of the amount of aerosol present. This scattering ratio, SR, as a function of wavelength, $\lambda$, and altitude, $j$, is calculated as

$\operatorname{SR}(\lambda, j)=\frac{I_{\text {meas }}(\lambda, j)}{C(\lambda) \cdot I_{\text {mod }}(\lambda, j)}$,

where $I_{\text {meas }}$ is the radiance as measured by OSIRIS, $I_{\bmod }$ is the modeled radiance expected from a molecular atmosphere and $C$ is an altitude normalization to help account for errors in the assumed air density and albedo. Radiances are modeled using SASKTRAN, a fully spherical, multiple scattering model using retrieved ozone profiles and neutral densities from ECMWF (Bourassa et al., 2008). Typically, these scattering ratios are inverted to produce aerosol extinction coefficients (Bourassa et al., 2007). However, this requires additional assumptions about the composition, break-up and subsequent evolution of the debris, which can be avoided if the scattering ratios are used directly. As these ratios are sufficient to distinguish areas of enhanced scattering, they are used for the detection of the meteoric debris and its subsequent removal in the analysis below. Despite the necessary assumptions, a conversion of the scattering ratios into aerosol extinction is of some interest and is attempted in Sect. 4.

However, this requires assumptions about the particle size and composition, and it is unlikely that the typical sulfate

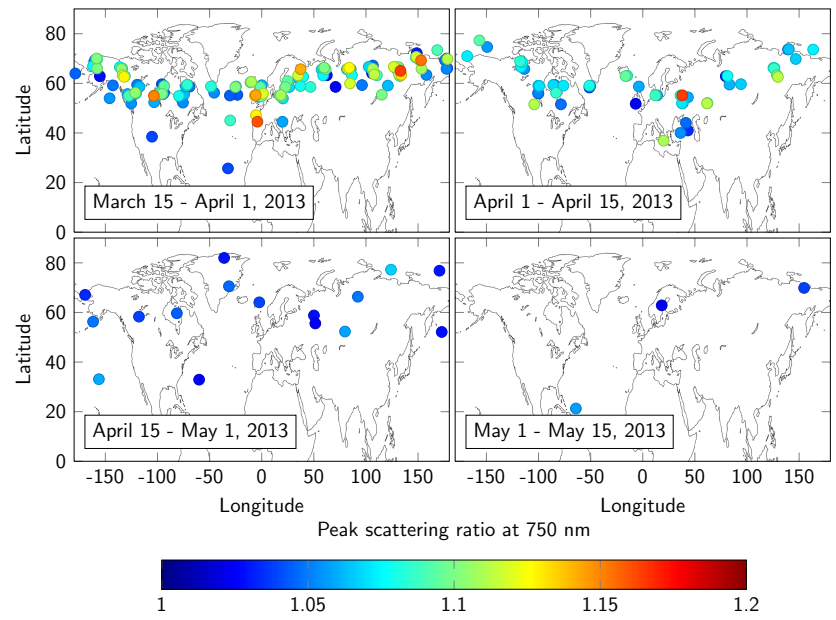

Fig. 2. Locations of scans that show meteoric enhancements. Color shows the $750 \mathrm{~nm}$ scattering ratio at the highest peak in the profile.

aerosol with a lognormal distribution is representative of the meteoric particles investigated here. With an inaccurate particle size and composition, inversion provides little additional information and so for this study measurements are left as scattering ratios. This is sufficient to distinguish areas of enhanced scattering and to monitor the removal of meteoric material.

An example of typical scattering ratios between 550 and $800 \mathrm{~nm}$ for two OSIRIS scans during the previous year with similar locations and illumination conditions is shown in Fig. 1a and b. Here, the Junge layer is present below approximately $30 \mathrm{~km}$, with a strong peak just below $20 \mathrm{~km}$. Above the Junge layer, little to no aerosol is present. Panels c through f show measurement vectors for four scans in 2013 following the meteor impact, which show a second layer of aerosol above the Junge layer between 30 and $35 \mathrm{~km}$. This is attributed to the Chelyabinsk meteor. Initially, the scattering due to aerosols at the high-altitude peak is approximately $10-15 \%$ of the total signal, with a peak near $34 \mathrm{~km}$ altitude. By the end of April enhancements closer to $5 \%$ are more typical, with a peak that has dropped to $31 \mathrm{~km}$.

\section{The Chelyabinsk meteor}

To help distinguish the meteor from the background conditions, a measurement is considered to contain meteoric aerosol if it meets two conditions:

1. The highest peak in the $750 \mathrm{~nm}$ scattering ratio must occur at least $18 \mathrm{~km}$ above the $380 \mathrm{~K}$ tropopause.

2. The magnitude of this peak must be at least 1.02 .

These criteria help to eliminate scans that have high aerosol loading at high altitudes due to isentropic transport from the tropics and ensure that the peak is above the noise 


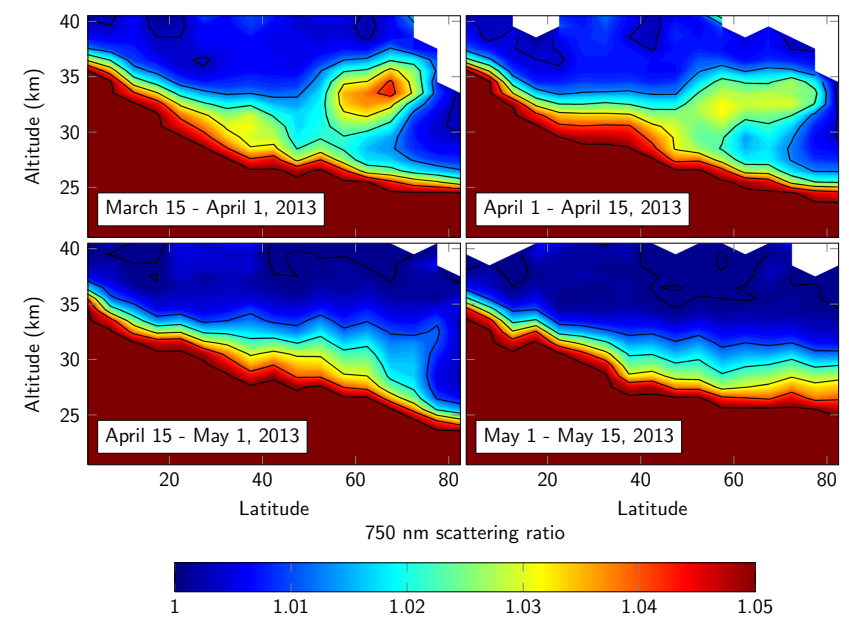

Fig. 3. Zonal average of $750 \mathrm{~nm}$ scattering ratios for four two-week time periods starting approximately one month after the meteor impact. Contours mark every $1 \%$ increase over background scattering up to $5 \%$.

threshold of the measurements. The locations of scans that meet these criteria are plotted in Fig. 2 in two-week intervals. Once OSIRIS is turned on in mid-March a strong belt of meteoric material is detected between $50^{\circ} \mathrm{N}$ and $70^{\circ} \mathrm{N}$. This coincides well with the analysis performed by Gorkavyi et al. (2013), who showed the meteor remnants circumnavigating the globe in a high-latitude belt within a week of the impact using OMPS (Rault and Loughman, 2013) measurements and trajectory analysis.

The altitude distribution of the material is also clear in zonal averages. Figure 3 shows zonal averages for the same time periods as Fig. 2. These averages include all scans from the time periods. At the end of March a clear enhancement is visible from 30 to $35 \mathrm{~km}$ altitude and between $50^{\circ} \mathrm{N}$ and $70^{\circ} \mathrm{N}$. By early April the enhancement is noticeably weaker and has begun to spread to lower latitudes. Throughout April the plume continues to decay and merge with the background aerosol, with essentially no enhancements visible by early to mid-May.

\section{Measurement inversion}

The nature of limb scatter measurements dictates that for accurate forward modeling the concentrations, phase functions and refractive indices of particles in the atmosphere must be known (or retrieved). The standard OSIRIS retrieval assumes that stratospheric aerosols are composed of spherical, hydrated sulfate particles with a lognormal size distribution typical of background loading conditions. Retrieval is then performed using the $750 \mathrm{~nm}$ wavelength to determine to aerosol extinction. This works well when the aerosol conforms to typical stratospheric conditions (Bourassa et al., 2012), but

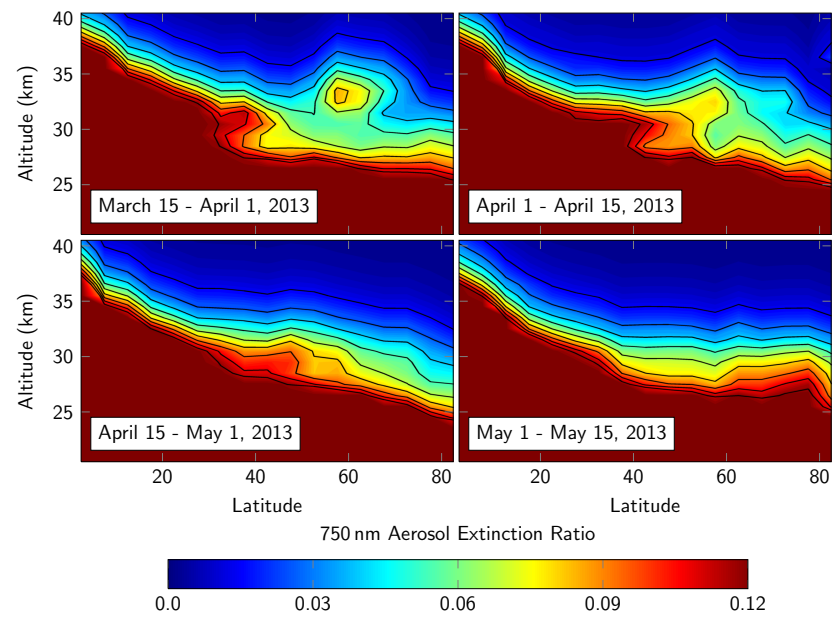

Fig. 4. Zonal average of $750 \mathrm{~nm}$ extinction ratios (aerosol/background) for the same time periods as Fig. 3 .

will have systematic biases if the assumptions regarding particle composition, size and shape are violated.

The composition of the Chelyabinsk meteor was primarily ordinary chondrite (Popova et al., 2013), suggesting that the assumption of hydrated sulfate is largely inaccurate. However, this is the same assumption as was made in the OMPS extinction retrievals performed by Gorkavyi et al. (2013), and so is maintained for comparison to this work. Figure 4 shows the retrieved aerosol extinction ratio at $750 \mathrm{~nm}$ for the same time periods as studied above. Here the extinction ratio is the ratio of retrieved aerosol extinction to the Rayleigh extinction at the same wavelength. Qualitatively, these results are in good agreement with the results of Gorkavyi et al. (2013), which showed a belt of meteoric debris approximately $5 \mathrm{~km}$ thick decaying until May, at which point it is essentially indistinguishable from the background. Quantitative comparison is more difficult due to the wavelength differences of the instruments and the assumptions made in the retrievals; however, both instruments retrieve extinctions in the low $10^{-6} \mathrm{~km}^{-1}$ range near the end of March at the peak of the plume. The error in this quantity is difficult to estimate without additional knowledge of the evolution of the meteoric debris and how this varies from the assumed microphysics.

\section{Conclusions}

The timing and location of meteoric detections by OSIRIS agree well with the analysis performed by Gorkavyi et al. (2013). The stratospheric influence of the Chelyabinsk meteor is visible using limb scatter techniques for approximately three months following the impact. OSIRIS measurements taken after 15 March show a band of meteoric material circling the globe between $50^{\circ} \mathrm{N}$ and $70^{\circ} \mathrm{N}$ at $35 \mathrm{~km}$, which 
decays into the background over the following two months. Aerosol retrievals suggest extinctions of the meteoric debris in the low $10^{-6} \mathrm{~km}^{-1}$ range near the end of March, although this is subject to large error due to the unknown nature of the microphysical properties.

Acknowledgements. This work was supported by the Natural Sciences and Engineering Research Council (Canada) and the Canadian Space Agency. Odin is a Swedish-led satellite project funded jointly by Sweden (SNSB), Canada (CSA), France (CNES) and Finland (Tekes).

Edited by: O. Torres

\section{References}

Bourassa, A. E., Degenstein, D. A., Gattinger, R. L., and Llewellyn, E. J.: Stratospheric aerosol retrieval with OSIRIS limb scatter measurements, J. Geophys. Res., 112, D10217, doi:10.1029/2006JD008079, 2007.

Bourassa, A. E., Degenstein, D. A., and Llewellyn, E. J.: SASKTRAN: A spherical geometry radiative transfer code for efficient estimation of limb scattered sunlight, J. Quant. Spectrosc., 109, 52-73, 2008.

Bourassa, A. E., Rieger, L. A., Lloyd, N. D., and Degenstein, D. A.: Odin-OSIRIS stratospheric aerosol data product and SAGE III intercomparison, Atmos. Chem. Phys., 12, 605-614, doi:10.5194/acp-12-605-2012, 2012.

Gorkavyi, N., Rault, D., Newman, P., Silva, A., and Dudorov, A.: New stratospheric dust belt due to the Chelyabinsk bolide, Geophys. Res. Lett., 40, 4734-4739, doi:10.1002/grl.50788, 2013.
Llewellyn, E., Lloyd, N. D., Degenstein, D. A., Gattinger, R. L., Petelina, S. V., Bourassa, A. E., Wiensz, J. T., Ivanov, E. V., McDade, I. C., Solheim, B. H., McConnell, J. C., Haley, C. S., von Savigny, C., Sioris, C. E., McLinden, C. A., Griffioen, E., Kaminski, J., Evans, W. F. J., Puckrin, E., Strong, K., Wehrle, V., Hum, R. H., Kendall, D. J. W., Matsushita, J., Murtagh, D. P., Brohede, S., Stegman, J., Witt, G., Barnes, G., Payne, W. F., Piche, L., Smith, K., Warshaw, G., Deslauniers, D. L., Marchand, P., Richardson, E. H., King, R. A., Wevers, I., McCreath, W., Kyrola, E., Oikarinen, L., Leppelmeier, G. W., Auvinen, H., Megie, G., Hauchecorne, A., Lefevre, F., de La Noe, J., Ricaud, P., Frisk, U., Sjoberg, F., von Scheele, F., and Nordh, L.: The OSIRIS instrument on the Odin spacecraft, Can. J. Phys., 82, 411-422, 2004.

Popova, O. P., Jenniskens, P., Emel'yanenko, V., Kartashova, A., Biryukov, E., Khaibrakhmanov, S., Shuvalov, V., Rybnov, Y., Dudorov, A., Grokhovsky, V. I., Badyukov, D. D., Yin, Q.-Z., Gural, P. S., Albers, J., Granvik, M., Evers, L. G., Kuiper, J., Kharlamov, V., Solovyov, A., Rusakov, Y. S., Korotkiy, S., Serdyuk, I., Korochantsev, A. V., Larionov, M. Y., Glazachev, D., Mayer, A. E., Gisler, G., Gladkovsky, S. V., Wimpenny, J., Sanborn, M. E., Yamakawa, A., Verosub, K. L., Rowland, D. J., Roeske, S., Botto, N. W., Friedrich, J. M., Zolensky, M. E., Le, L., Ross, D., Ziegler, K., Nakamura, T., Ahn, I., Lee, J. I., Zhou, Q., Li, X.H., Li, Q.-L., Liu, Y., Tang, G.-Q., Hiroi, T., Sears, D., Weinstein, I. A., Vokhmintsev, A. S., Ishchenko, A. V., Schmitt-Kopplin, P., Hertkorn, N., Nagao, K., Haba, M. K., Komatsu, M., Mikouchi, T., and the Chelyabinsk Airburst Consortium: Chelyabinsk Airburst, Damage Assessment, Meteorite Recovery, and Characterization, Science, 342, 1069-1073, 2013.

Rault, D. F. and Loughman, R. P.: The OMPS Limb Profiler Environmental Data Record Algorithm Theoretical Basis Document and Expected Performance, 2013.

Yeomans, D. and Chodas, P.: Additional Details on the Large Fireball Event over Russia on Feb. 15, 2013, available at: http://neo. jpl.nasa.gov/news/fireball_130301.html (last access: 16 September 2013), 2013. 